\title{
Research Article \\ Electrical Capacitance Probe Characterization in Vertical Annular Two-Phase Flow
}

\author{
Grazia Monni, ${ }^{1}$ Mario De Salve, ${ }^{1}$ Bruno Panella, ${ }^{1}$ and Carlo Randaccio ${ }^{2}$ \\ ${ }^{1}$ Dipartimento Energia, Politecnico di Torino, Corso Duca degli Abruzzi 24, 10129 Torino, Italy \\ ${ }^{2}$ SIET S.p.A., Via Nino Bixio 27, 29121 Piacenza, Italy \\ Correspondence should be addressed to Bruno Panella; bruno.panella@polito.it
}

Received 1 August 2013; Accepted 27 September 2013

Academic Editor: Eugenijus Ušpuras

Copyright (C) 2013 Grazia Monni et al. This is an open access article distributed under the Creative Commons Attribution License, which permits unrestricted use, distribution, and reproduction in any medium, provided the original work is properly cited.

\begin{abstract}
The paper presents the experimental analysis and the characterization of an electrical capacitance probe (ECP) that has been developed at the SIET Italian Company, for the measurement of two-phase flow parameters during the experimental simulation of nuclear accidents, as LOCA. The ECP is used to investigate a vertical air/water flow, characterized by void fraction higher than $95 \%$, with mass flow rates ranging from 0.094 to $0.15 \mathrm{~kg} / \mathrm{s}$ for air and from 0.002 to $0.021 \mathrm{~kg} / \mathrm{s}$ for water, corresponding to an annular flow pattern. From the ECP signals, the electrode shape functions (i.e., the signals as a function of electrode distances) in singleand two-phase flows are obtained. The dependence of the signal on the void fraction is derived and the liquid film thickness and the phase's velocity are evaluated by means of rather simple models. The experimental analysis allows one to characterize the ECP, showing the advantages and the drawbacks of this technique for the two-phase flow characterization at high void fraction.
\end{abstract}

\section{Introduction}

The design of new nuclear reactors requires carrying out integral and separate effect tests on simulation facilities, as well as performing safety systems verification and safety code validation. Within the framework of an Italian $R \& D$ program on nuclear fission, managed by ENEA and supported by the Ministry of Economic Development, the SPES3 (pressurized simulator for safety experiments) experimental facility, described by Carelli et al. [1], able to simulate the innovative small and medium size (PWR pressurized water reactor) nuclear reactors, is being built and will be operated at the SIET Company laboratories in Piacenza, Italy. In such facility, some design and beyond design basis accidents, like loss of coolant accidents (LOCAs), with and without the emergency heat removal systems, will be simulated [2]. The experimental data, concerning a series of primary and secondary loops breaks, will be fundamental for the certification process of such reactors. New accidental transients, following the Fukushima accident learning lesson, will be also studied. The availability of such a complex plant allows performing other exploitation, and studies are foreseen for using it in a wider field of application for integral layout SMR simulation.
An accurate accident analysis requires the measurement of the mixture mass flow rate occurring in a LOCA, when a piping break occurs at high temperature and pressure. For this reason, instruments and methodologies to evaluate mass flow rates, at the break and at other locations of the plant, need to be developed, considering the severe thermal-hydraulic conditions during the blowdown phase (the flow is critical, the average void fraction is higher than $90 \%$, and the flow pattern is annular).

Typically, a set of instruments (Spool Piece) must be installed in order to evaluate the mass flow rate of the twophases [3-5]. One of such instruments has to be able to measure the void fraction and to identify the flow pattern. In fact, the response of a meter in two-phase flow tends to be highly sensitive to the flow pattern, to the upstream configuration, and to the flow history. As a first step to achieve this purpose, the present study deals with the characterization of a capacitive meter device for annular flow. The behavior of the sensor is tested and advantages and drawbacks are highlighted.

The void fraction in the region of interest is one of the key parameters in gas-liquid two-phase flow systems, as it is used for determining several other important parameters (density 
and viscosity, velocity of each phase, etc.) and for predicting heat transfer and pressure drops. It can be measured by using a number of techniques, including radiation attenuation $(X-$ or $\gamma$-ray or neutron beams) for line or cross section averaged values, optical or ultrasound techniques for local and chordal void fraction measurement, impedance techniques by means of capacitance or conductance sensors for local or volumetric measurements, and quick-closing valves for direct measurement of the volumetric void fraction. The use of the different techniques depends on the applications and whether a volume averaged or a local void fraction measurement is required. All the different techniques are based on the use of a sensor that is sensitive to the variation of the physical properties of the phase mixture and therefore able to detect the presence of one of the phases.

The impedance method is based on the fact that the liquid and gas phases have different electrical conductivity and relative permittivity, and the electrical impedance of a mixture is usually different by the impedance of each component. The gases are generally poor conductors with a low dielectric constant, while the liquids, although not good conductors, assume higher value of the dielectric constant due to a greater concentration of dipoles. In the electrical impedance void meters, the resistive and/or the capacitive response of the two-phase flow region to an electrical field is measured and the resultant resistance and/or capacitance value (impedance) is used to estimate the void fraction. Impedance sensors have been used successfully to measure time and volume averaged void fraction, and their instantaneous output signal has been used to identify the flow pattern in the work of Rochal et al. [6]. The fast response of the impedance meters allows obtaining information about virtually instantaneous void fractions and their distributions across a pipe section. This type of meter can work at high pressure and temperature (in this case the signal is corrected taking into account the effect of pressure and temperature variation on the signals) and also with high flow velocity, and it is more attractive than other techniques from an economic point of view. The measurements of the void fraction with impedance sensors are quasi-local: the sensor determines the percentage of both phases not strictly in a selected cross section of the pipe but in a certain volume, based on the electrodes geometry. The measurements of the impedance take place in a volume defined by the lines of an electric field associated with the electrodes system. The reference control volume for the electrode probe is a function of the electrode surface, of their distance, and of the electrical properties of the medium. Concerning the classical impedance probes, one of the most important drawbacks is the strong sensitivity to the flow pattern that can produce some ambiguity in the signal interpretation; for example, if the sensor produces the same signal for two different flow conditions, a criterion for the flow pattern identification has to be developed.

To address this problem, in the last years, tomography sensors using the impedance probes have been developed and several researches have been carried out [7-9]. The impedance measurements are taken from a multielectrode sensor surrounding a process vessel or a pipeline. The working principle consists of sending a sinusoidal signal to an electrode and measuring the output signal in the remaining electrode. This procedure is repeated for all the other electrodes pairs until a full rotation is completed to get a set of measurements. Each dataset is interpreted by algorithms to compute a cross-sectional electrical capacitance distribution.

The concentration of each phase can be evaluated from the electrical permittivity values of each phase. The advantage is its excellent time resolution arising from the very fast measurement of electrical resistances, while the drawback is the relatively low spatial resolution, since the phases distribution reconstruction is based on measurements at the periphery of the sensor. This problem is stressed in presence of an annular flow as the liquid film at the wall creates a preferential path for the electric field lines that shields the core region and makes the sensor poorly sensitive to the void fraction. The range of interest of the flow parameters, in steady state and transient conditions, has been investigated by means of the RELAP5 code [10] and, for each line of the SPES3 facility, the range of measurement of the different parameters has been identified; the performed simulations show that, in a relative long period of the transients, the two-phase flow corresponds to an annular flow pattern, characterized by very high void fraction and high flow velocity, so that the selected instruments of the Spool Piece must be sensitive to the flow in such conditions. In order to address the drawback, the present study authors have designed and developed a sensor consisting of nine external electrodes and an internal one.

In this paper, the sensor design and the experimental characterization at very high void fraction and in presence of annular air/demineralised-water flow are described. The possibility to obtain information about other thermal-hydraulic parameters is also discussed and an evaluation of the response of the sensor at the variation of the flow pattern has been carried out.

Concerning the annular flow pattern, a large number of experimental and theoretical studies have been performed by several authors (see [11-14]). The flow pattern can be described in a simplified model as a liquid film flowing on the wall of the tube and a gas phase flowing in the center (core flow): some rate of the liquid phase is entrained as small droplets in the gas core. As the liquid flow rate is increased, the droplet concentration in the gas core increases and the droplet coalescence occurs leading to large lumps or streaks as wispy liquid inside the gas core. It is hypothesized that the occurrence of agglomeration is due to a fundamental instability of the gas-droplet core flow: if positive wave growth coefficients are present, the system is classified as unstable and belongs to the wispy-annular flow regime [12], while fully stable systems are classified as belonging to the annular flow regime.

The annular flow is quite difficult to be observed using ordinary visualization techniques since the liquid film in this regime tends to screen the core region. The present study investigates also the use of the ECP sensor to detect the phase distribution inside the core region of the annular flow. 


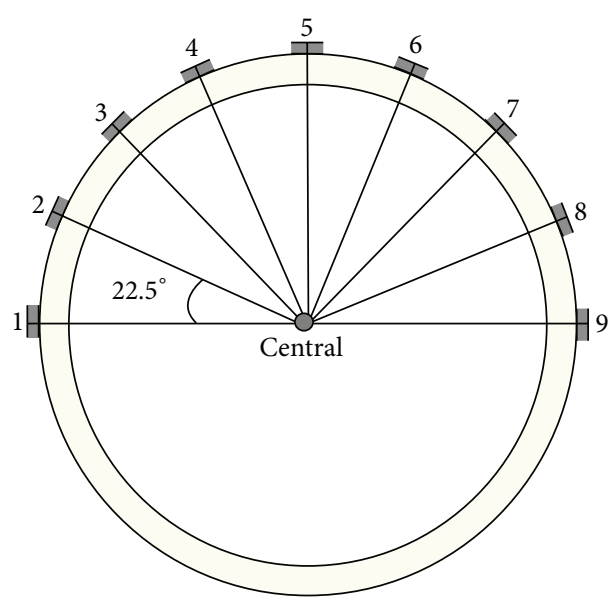

FIgURE 1: Schematic of the ECP.

\section{Electrical Capacitance Probe (ECP)}

The sensor ECP has been developed by the SIET Company and consists of 10 electrodes: 9 external and one central (Figure 1). The inner and the outer diameters of the Plexiglas pipe, where the probe is mounted, are $80 \mathrm{~mm}$ and $90 \mathrm{~mm}$. The external electrodes (steel stripes of $400 \mathrm{~mm}$ length and $5 \mathrm{~mm}$ width) are spaced with $22.5^{\circ}$ angle only on a halfcircumference of the pipe, due to the vertical flow symmetry. The angle corresponds to an external chord of $17.56 \mathrm{~mm}$ and an internal chord of $15.6 \mathrm{~mm}$. The sensor geometry has been developed in half of the pipe circumference as the symmetry of the vertical flow has been verified. The main purpose of the sensor is the evaluation of the effect of the angular electrode distance on the output signal.

The external electrodes are pasted on the Plexiglas pipe and are welded with the conductor that allows the link with the electronic part, while the internal electrode is connected through a metallic support at the outside of the pipe.

The electrodes are connected in an electronic circuit by several reed relays and two insulation transformers in order to prevent common mode disturbances. The reed relays technology has been selected for its simplicity and its features: very small closing and opening time, very high resistance when open, very small resistance when closed, very small electrical capacity, and long life.

Each external electrode is connected, at the upper and lower extremity, to two reed relays to activate, in a predefined sequence, the excited electrode and the measuring one; the internal one is connected only in the upper extremity and it is always used as a measuring electrode, when the corresponding reed relay is activated.

\section{Experimental Facility and Test Section}

The experimental facility consists of the feed water and the feed air loops equipped with instruments to measure the single-phase flow parameters (flow meter, temperature, and pressure). The water mass flow rate is measured by

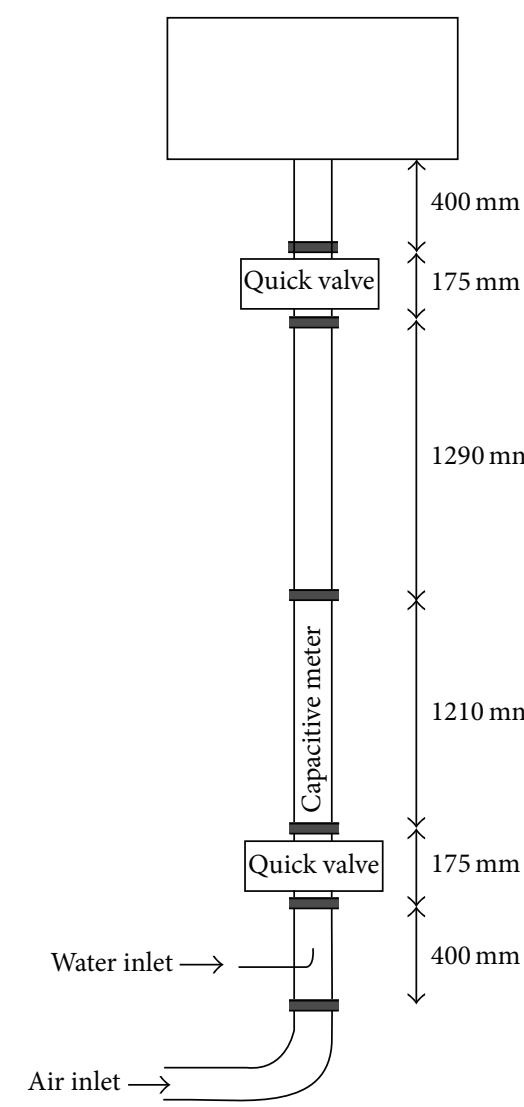

(a)

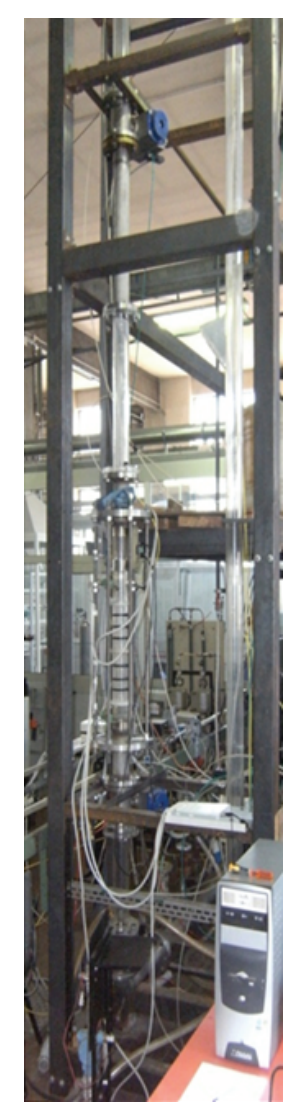

(b)
FIGURE 2: Experimental facility: test section schematic (a) and picture (b).

a rotameter, while the air flow rate is measured by a calibrated orifice flow meter, whose accuracy is $2 \%$ full scale value.

The facility, which is shown in Figure 2, consists of a vertical Plexiglas tube ( $80 \mathrm{~mm}$ inside diameter and $4 \mathrm{~m}$ long). The test section is transparent (Plexiglas) in order to visualize the flow pattern. The air and the water are injected inside the pipe at the bottom of the tube and mix at about $400 \mathrm{~mm}$ from the test section inlet (Figure 2); the water is injected through a porous bronze. The $2.5 \mathrm{~m}$ long test section is equipped with two pneumatic quick-closing valves (QCVs) to measure the volumetric void fraction; the uncertainty associated with the void fraction measurement has been estimated as $\Delta \alpha=$ \pm 0.0012 .

Downstream of the upper valve the air and the water are separated in a tank at atmospheric pressure. Experiments are carried out at a constant water temperature of $20^{\circ} \mathrm{C}$, and the absolute pressure is measured at the inlet of the test section by a pressure transducer Rosemount 3051/1.

The presence of the internal electrode (whose length is $400 \mathrm{~mm}$ and diameter is $5 \mathrm{~mm}$ ) in the center of the pipe affects the mechanisms of the dispersed flow; a liquid film has been observed on it. Okawa et al. [15] have shown in their experiments that the deposition rate of droplets was markedly increased if the present flow obstacle was placed inside the flow channel and the deposition rate was approximately 
1.5 times larger than the deposition rate with no obstacle. The presence of the central obstacle together with a higher diameter and the coaxial liquid injection can affect the waves in the liquid film and the droplet coalescence in the core region also at rather low liquid superficial velocities.

\section{Experimental Methodology and Signal Acquisition}

The signals from the sensor are acquired by using the NI USB-6259 DAQ (Data AcQuisition) and are managed using a LabVIEW program. The predefined measurement sequence is read and the corresponding reed relay is activated by using a $5 \mathrm{~V} \mathrm{DC}$ signal. The excitation signal is sent to the electrodes (sinusoidal signal with an excitation frequency $f_{\text {ex }}=25 \mathrm{kHz}$ and an amplitude of $5 \mathrm{~V}$ ) and the output signal is sampled using a frequency $f_{\mathrm{ac}}$ of $250 \mathrm{kHz}$; the (RMS root mean square) value corresponding to 2000 samples is acquired. The excitation frequency has been chosen considering that the experiments are carried out with demineralised water; in this case, the sensor output signal is directly proportional to the fluid capacitance.

The measurement sequence is defined as follows: the external electrodes are excited in sequence and for each one the output signal of the other external electrodes are read; after that scan the output signal relative to the central electrode is acquired for each excited external electrode. For every couple of electrodes, the sampling time of RMS value is about $33 \mathrm{~ms}$ so that the total scanning time depends on the selected measurement sequence. Before each set of experimental runs, the static values of the signals for air and water are measured. Then, for each run, the mass flow rates of water and air are fixed and, when the flow is in steady state, the pressure value and the signals from the ECP sensor are acquired. At the end of the measurement sequence, the volume averaged void fraction is measured by means of the quick-closing valves technique.

\section{Experimental Data Range}

In order to evaluate the response of the sensor at high void fractions, corresponding to annular flow, a mixture of air and demineralized water is introduced in the test section. The mass flow rate ranges from 0.094 to $0.15 \mathrm{~kg} / \mathrm{s}$ for air and from 0.002 to $0.021 \mathrm{~kg} / \mathrm{s}$ for water, corresponding to a void fraction higher than $95 \%$. The tests have been performed at atmospheric pressure. The volumetric void fraction (measured with QCV technique) increases with gas superficial velocity $J_{g}$ and decreases with $J_{l}$, as shown in Figure 3.

Figure 4 shows the volumetric void fraction as a function of the flow quality: a small flow quality variation at constant $J_{l}$ corresponds to large void fraction variations, while the slope of the void fraction versus $x$ increases as $J_{l}$ decreases.

\section{Capacitance Probe Experimental Results}

The first ECP qualification step is the characterization of the sensor for single-phase conditions; so, before each test,

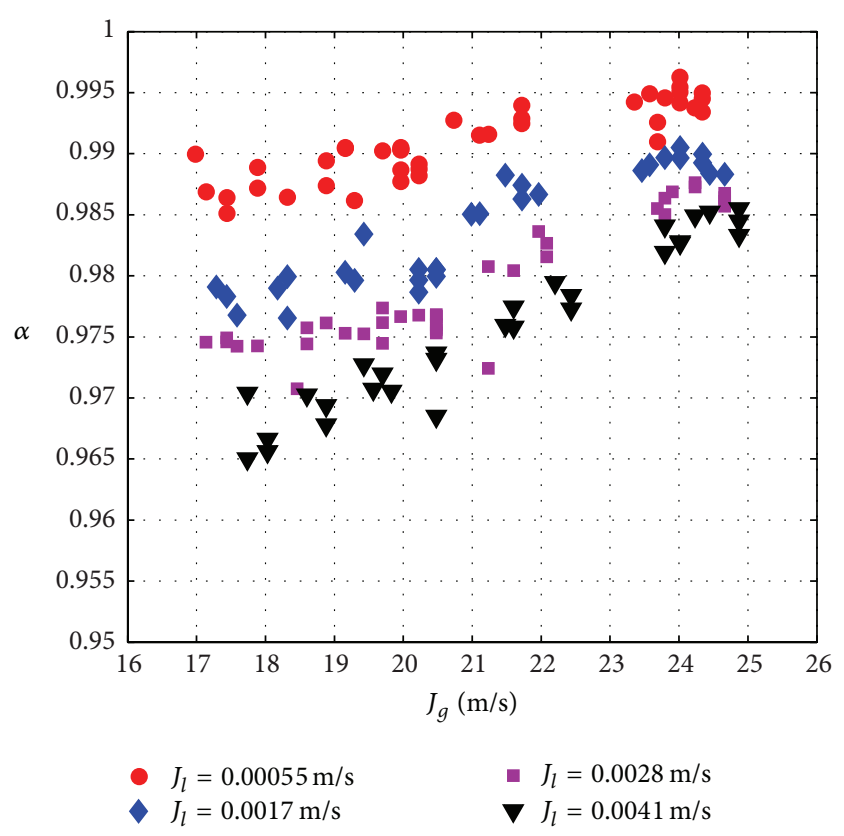

FIGURE 3: Experimental volumetric void fraction as a function of water and air superficial velocities.

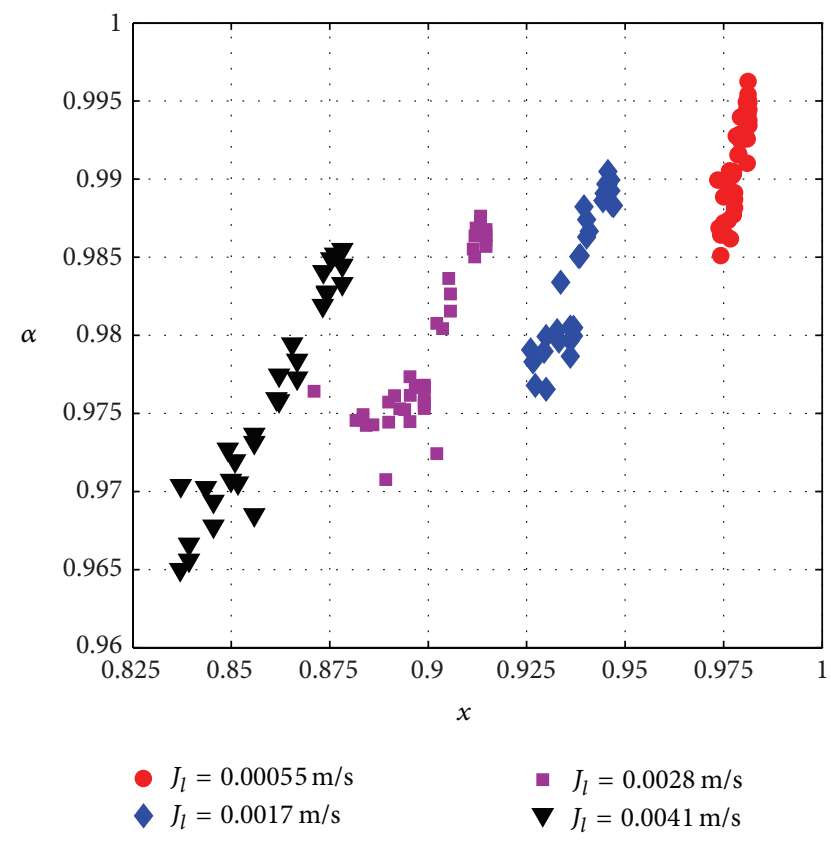

FIgURE 4: Experimental volumetric void fraction as a function of the flow quality at different water superficial velocity.

measurements with air and demineralized water have been carried out in order to evaluate the signal noise level and to normalize the signals for two-phase flows; the single-phase measurements are used to determine the electrodes shape function of the sensor. In Figure 5, the RMS signals measured between electrode 1 and the other external electrodes are presented, as a function of the value of the angle $\theta$ between the electrodes. The measured RMS value is proportional to 


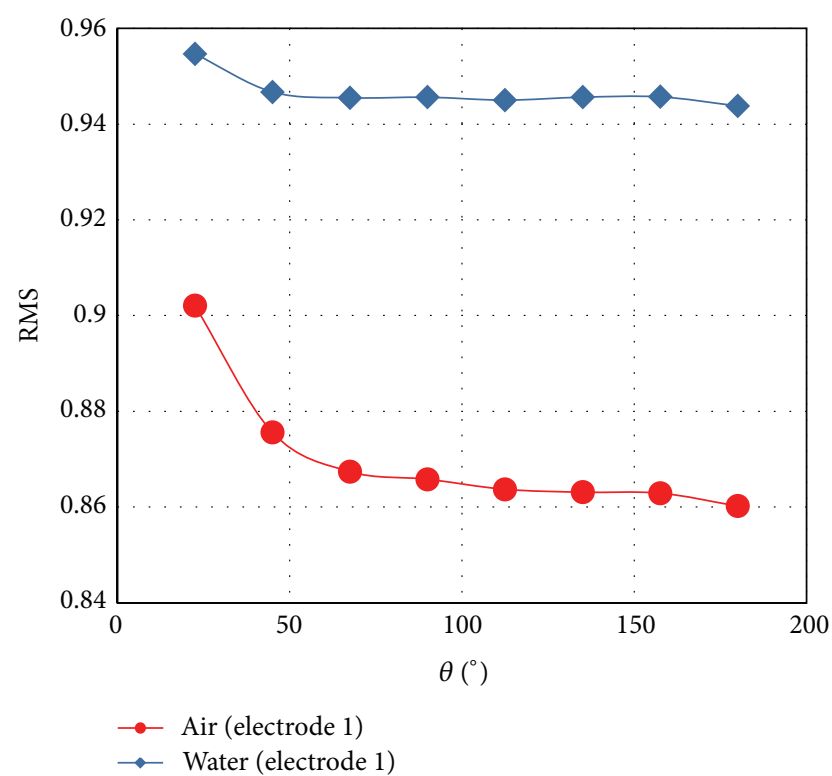

Figure 5: Single-phase ECP signals as a function of the angle $\theta$ for the excited electrode 1.

the electrical capacitance between the measuring electrodes; it also depends on the excitation frequency and on the resistance that is different between air, water, and two-phase mixture, also with demineralized water. As shown in Figure 5, the signal variation range is very limited due to the presence of the quite large Plexiglas thickness $(5 \mathrm{~mm})$ and to the absence of any signal amplification.

Moreover, the theoretical ratio between the water electrical permittivity and the air electrical permittivity, which equal to 80 , is reduced, in the practical case, at a value from 1.05 to 1.1 depending on the electrodes distance. The ratio is lower at $\theta=22.5^{\circ}$ due to the strong influence of the wall. The angle dependence is higher for the signal measured in air flow, while it seems limited for single-phase water flow.

For each electrodes combination, the ratio $\mathrm{RMS}_{g} / \mathrm{RMS}_{l}$ shows a rather high repeatability. The ratio of the two-phase RMSs, obtained by the measurements between the external electrodes, as a function of the angle $\theta$ is shown in Figure 6.

The analysis of the signals of the central electrode shows a higher sensitivity due to the direct contact of the probe with the mixture. In this case, the mean $\mathrm{RMS}_{g} / \mathrm{RMS}_{l}$ ratio is equal to $0.582 \pm 0.002$.

In order to take into account the single-phase signal variations, the two-phase flow measured values are normalized as follows:

$$
V_{i j}^{*}=\frac{\mathrm{RMS}_{\mathrm{TP}-i j}-\mathrm{RMS}_{l-i j}}{\mathrm{RMS}_{g-i j}-\mathrm{RMS}_{l-i j}},
$$

where the subscript $i j$ identifies the measuring electrodes combination.

Because of the physical differences between the internal and external electrode response, the signal of external and internal electrodes has been analyzed separately.

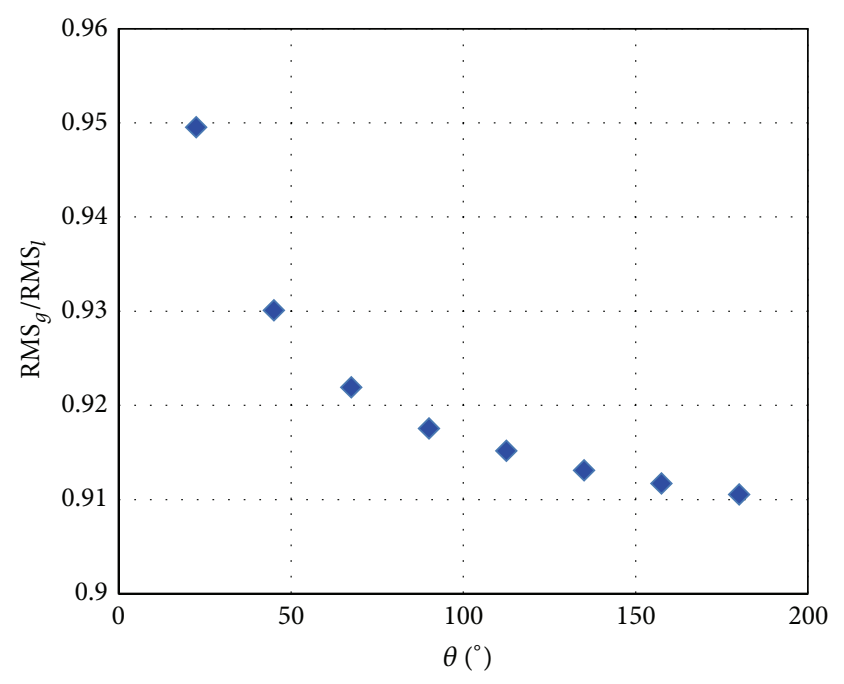

FIgURE 6: Single-phase ECP signals ratio as a function of the angle $\theta$, for the excited electrode 1 .

6.1. External Electrodes Signals. In order to evaluate the behavior of the sensors as a function of the mean void fraction, only the $i-j$ combination signals are considered (deriving the mean value and the standard deviations); while, in order to evaluate the interface phenomena in the liquid film and in the core region, the time dependent signals (an example is reported in Figure 7 for the electrodes combination 1-2 and test volumetric void fraction $\alpha$ equal to 0.995 (a) and 0.977 (b)) have to be considered. The signals evolution is shown in Figure 7: the single-phase signal is very stable in time so that the two-phase flow signals fluctuation can be related with the dynamic evolution of the flow; the third digit of the RMS has to be considered in order to take into account the film and the core flow dynamics. In Figure 7 the signal has been compared with water or air depending on the nearest mean RMS value.

Each combination is analyzed in terms of dependence on the fluid-dynamic quantities (experimental void fraction, superficial velocities of air and water) and geometry parameters $(\theta)$. A typical set of curves is reported in Figures 8 and 9. The sensor is sensitive to very little variation of the void fraction and this variation is detected from all the measuring electrodes combinations. As reported in the following pictures, the normalized signal $V_{i j}^{*}$ is a function of angle $\theta$, liquid film thickness $\delta$, and volumetric void fraction $\alpha$ (measured by the QCV technique).

The relationship between the capacitance and the void fraction depends not only on the dielectric values of the two-phases, but also on the surfaces of the sensors, on the separation distance between the two electrodes, and on the voltage distribution inside the measurement volume, which in turn depends on the phases distribution.

As regards the flow pattern, it is possible to develop a qualitative model for the signal variation: in the annular flow, the measurements taken from the external electrodes are not very sensitive to the core region flow, because the preferential path of the electrical field lines is located in 


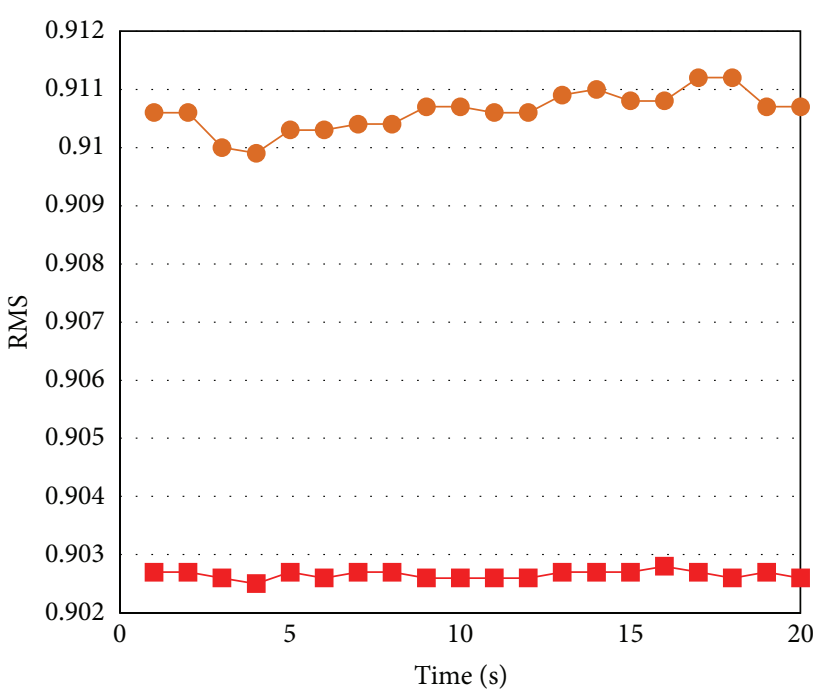

Electrodes combination: 1-2

$\rightarrow$ Air

$\multimap \alpha=0.995$

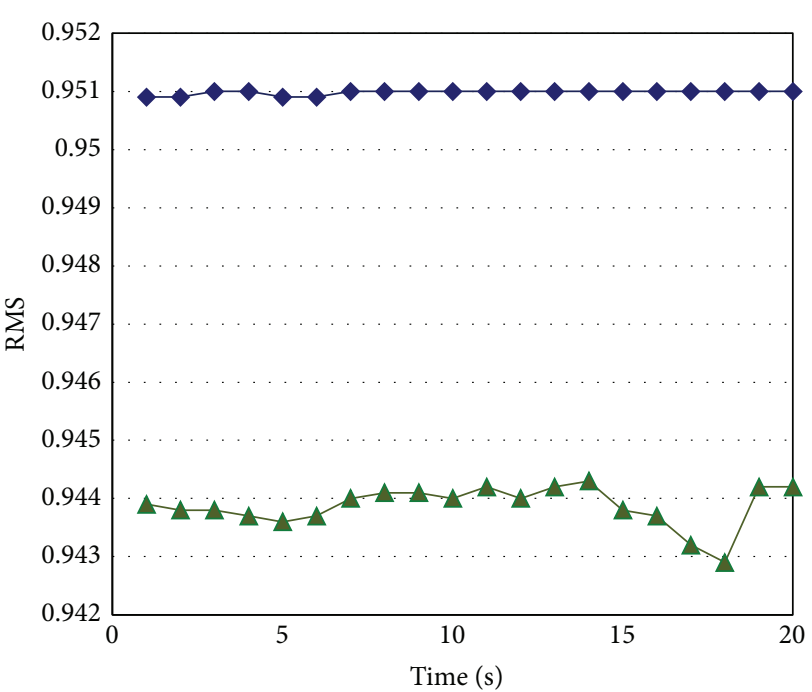

Electrodes combination: 1-2

$\rightarrow$ Water

$\neg \alpha=0.977$

(a)

(b)

FIGURE 7: RMS time evolution for 1-2 electrodes combination compared with the single-phase RMS time evolution: (a) $\alpha=0.995$; (b) $\alpha=$ 0.977 .

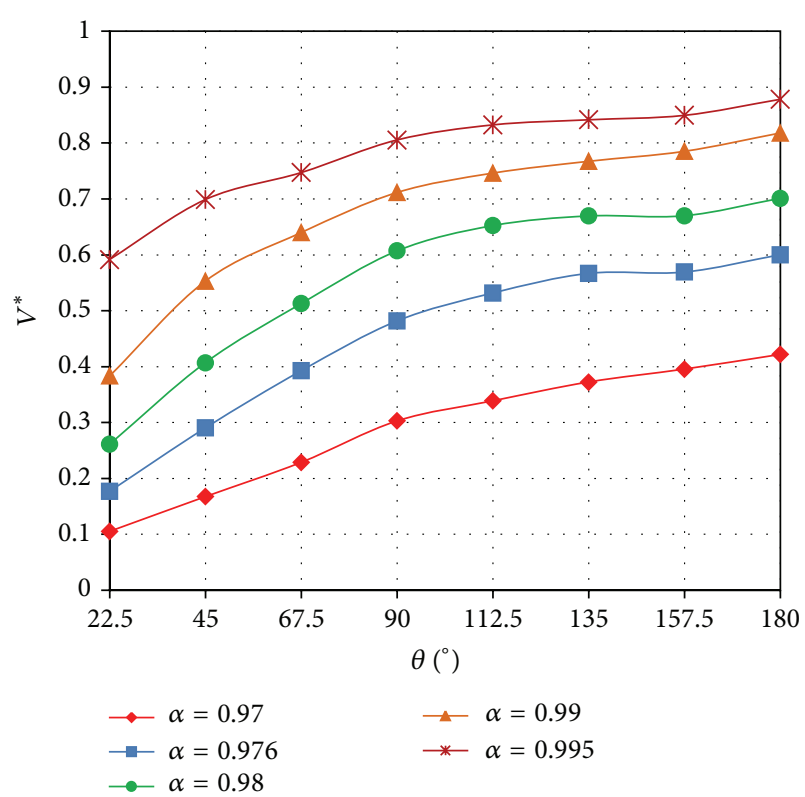

FIgURE 8: Normalized signal $V_{i j}^{*}$ for $i=1$ and $j=2-9$ as a function of angle $\theta$ for different experimental volumetric void fractions $\alpha$.

the continuous liquid film. The analysis of the signal shows that the measurement, taken between close electrodes $\theta=$ $22.5^{\circ}$ ), is more sensitive to the presence of the liquid film compared to the electrodes having higher distances, whose signal is affected by the flow distribution in the core region. In the hypothesis of axial symmetric flow, and in order to evaluate the sensor sensitivity to the mean void fraction

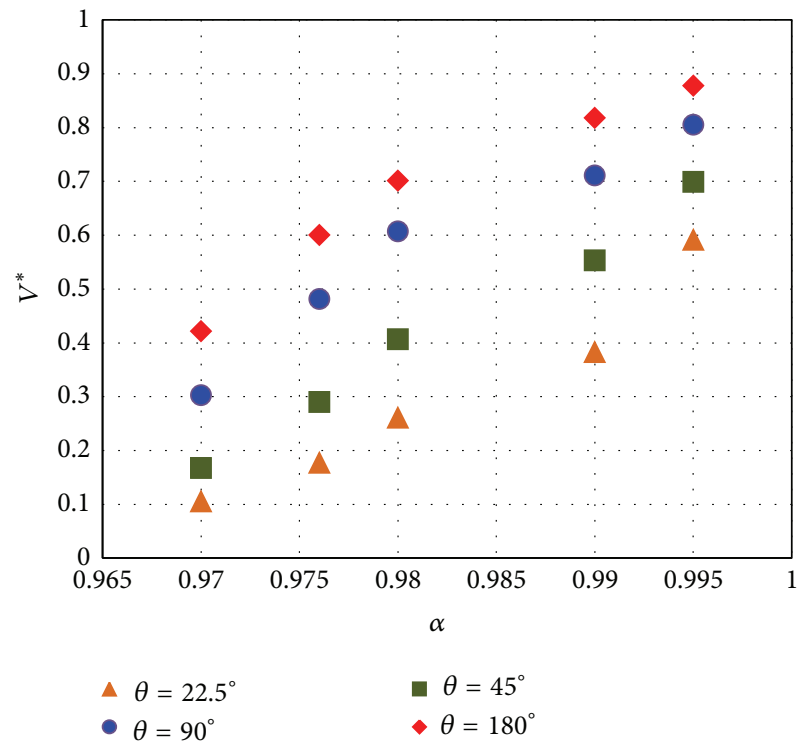

FIGURE 9: Normalized signal $V_{i j}^{*}$ as a function of the experimental volumetric void fraction $\alpha$ for different angles $\theta$.

variation, all the signals measured between electrodes, placed at the same angular distance, are used to evaluate the average normalized signal at the angle $\theta$. The average signals measured between electrodes at $22.5^{\circ}, 45^{\circ}, 90^{\circ}$, and $180^{\circ}$ are presented in Figure 10 as a function of the volumetric void fraction measured by the QCV technique. $V_{i j}^{*}$ (1) increases with $\theta$ at constant void fraction and approaches the air value at higher angular distance. No significant difference has been 


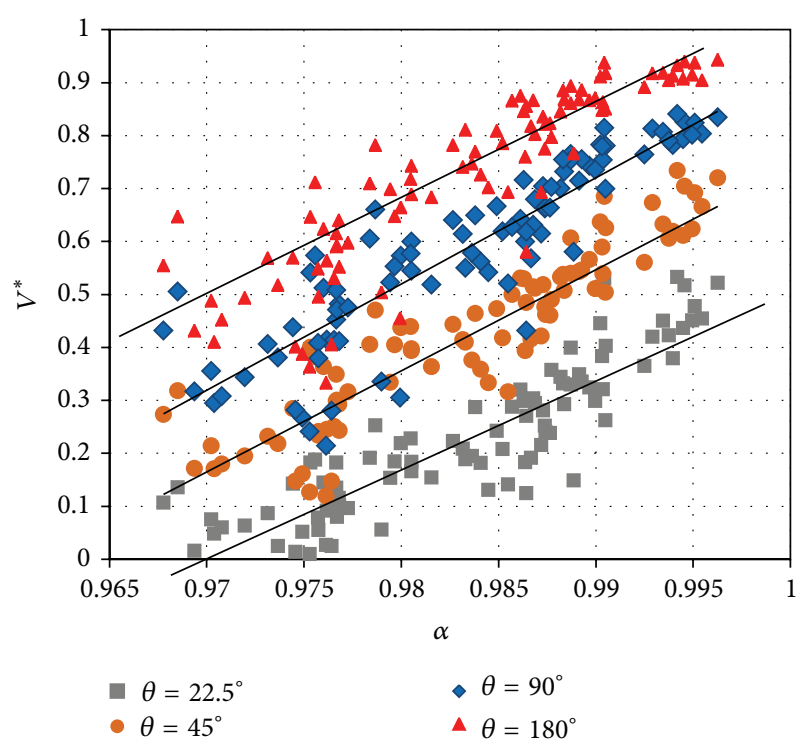

Figure 10: Mean signal measured in the external electrodes as a function of the experimental volumetric void fraction $\alpha$.

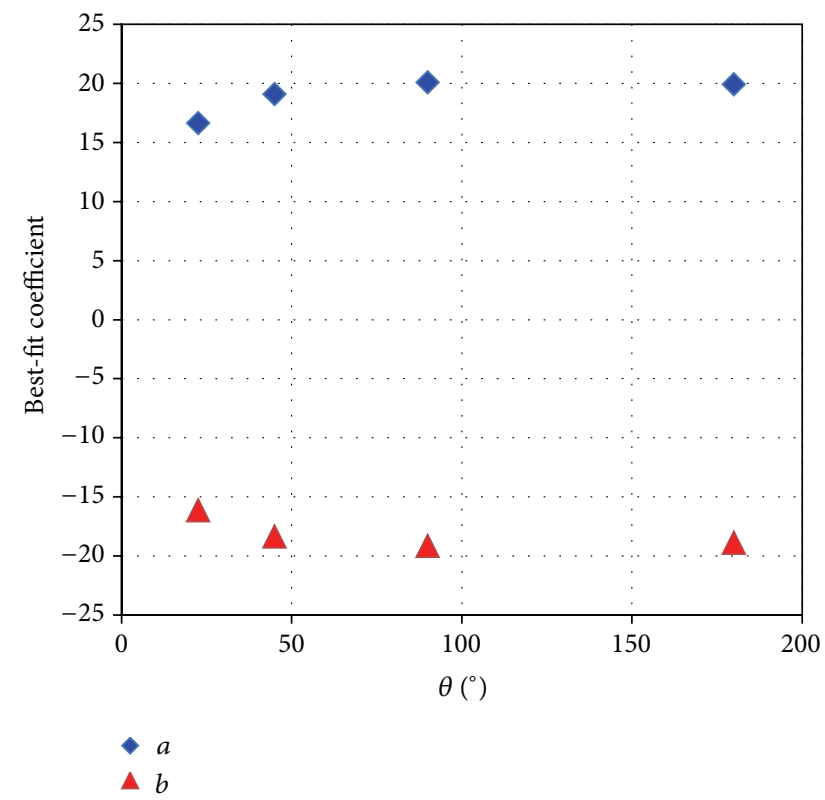

FIGURE 11: Best-fit coefficient dependence on the measuring angle $\theta$ for the curves shown in Figure 10; $a$ : slope, $b$ : intercept.

found between the signals of electrodes at $90^{\circ}$ and $132.5^{\circ}$ and at $157.5^{\circ}$ and $180^{\circ}$.

In Figure 11, the best-fit coefficients ( $a$ : slope, $b$ : intercept) of the curves reported in Figure 10 are shown. The curves are parallel for angles higher than $45^{\circ}$, while for the angles equal to $22.5^{\circ}$ and $45^{\circ}$ the signal dependence is different, due to the larger effect of the Plexiglas wall and of the liquid film thickness.

6.2. Central Electrode Signals. The signal of the central electrode, which is in direct contact with the fluid, is sensitive

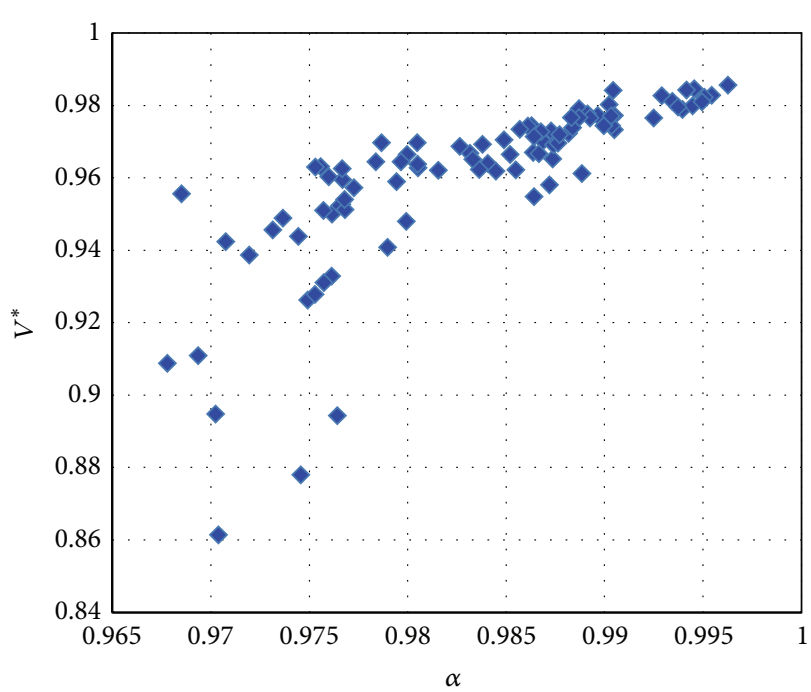

FIGURE 12: Mean signal measured in the central electrode as a function of the experimental volumetric void fraction $\alpha$.

to the mean cross section void fraction and could be directly related to the measured void fraction and to the amount of liquid droplets in the core region.

In Figure 12, the mean signal measured between the central electrode $(j=10)$ and the external electrodes $(i=$ $1: 9)$ is represented as a function of the experimental void fraction, measured by means of the QCV technique: the signal depends linearly on the void fraction at values higher than 0.98 and it is characterized by a higher standard deviation at lower values. In the tested range, the observed flow pattern is annular, with a rather low turbulence at the film interface, for liquid superficial velocities lower than $0.00152 \mathrm{~m} / \mathrm{s}$, while, at higher water mass flow rates and void fraction values lower than 0.98 , the flow pattern tends to become more turbulent with a greater mass of liquid that is entrained inside the core region as previously discussed.

The annular flow pattern is more regular at higher experimental void fraction as it is shown in Figure 12.

6.3. Annular Flow Model and Signals Interpretation. Due to the symmetry of the flow, the annular flow regime in a vertical channel can be analyzed in a simplified scheme as a liquid film region and a core region. The liquid film is characterized in terms of film thickness, frequency, and amplitudes of the waves at the liquid-gas interface, while the core region is characterized in terms of the mean void fraction value. By increasing the air flow rate, the liquid entrainment from the film to the gas core increases, while by increasing the water flow rate the amplitude of the waves increases and the flow tends to become more turbulent with a higher fraction of the water phase that is entrained in the core region and with an irregular wavy film flow.

In order to analyze the experimental results, some relevant flow parameters have been expressed by means of a simplified model. The parameters evaluated with the model 
are then used to interpret the sensor signals. In an annular flow, the void fraction can be written as follows:

$$
\alpha=\alpha_{c} \cdot\left(1-\alpha_{d}\right),
$$

where

$$
\begin{gathered}
\alpha_{d}=\frac{A_{d}}{A_{c}}, \\
\alpha_{c}=\frac{A_{c}}{A}=1-\alpha_{f},
\end{gathered}
$$

where $A_{c}$ is the core region area, $\alpha_{d}$ is the cross section fraction occupied by the droplets in the core, $\alpha_{c}$ is the fraction of the pipe cross section occupied by the core region, and $\alpha_{f}$ is the fraction of the pipe cross section occupied by the film region. Then, the value of $\alpha_{c}$ is an indirect index of the liquid film thickness.

Ishii and Mishima [13] derived the criteria for the onset of entrainment based on the balance of the forces acting on the waves to characterize the interface evolution in annular flow. The fraction of the liquid flux flowing as droplets $\left(E_{\infty}\right)$ is derived by Ishii and Mishima [13] and Hazuku et al. [14] as follows:

$$
E_{\infty}=\tanh \left(7.25 \cdot 10^{-7} \cdot \mathrm{We}^{1.25} \cdot \mathrm{Re}_{f}^{0.25}\right),
$$

where the Weber number is

$$
\mathrm{We}=\frac{\rho_{g} \cdot J_{g}^{2} \cdot D}{\sigma}\left(\frac{\rho_{l}-\rho_{g}}{\rho_{g}}\right)
$$

and the Reynolds number is

$$
\operatorname{Re}=\frac{\rho_{l} \cdot J_{l} \cdot D}{\mu_{l}},
$$

where $\rho_{g}, \mu_{g}, J_{g}$ and $\rho_{l}, \mu_{l}, J_{l}$ are respectively the density, the dynamic viscosity, and the superficial velocity of air (subscript $g$ ) and water (subscript $l$ ), while $\sigma$ is the surface tension.

In the present tests, the liquid Reynolds number $\operatorname{Re}_{l}$ ranges from 44 to 332 and the Weber number We ranges from 2200 to 7000 .

In a pure annular flow, the liquid flows only in the film region, so the maximum value of liquid film thickness $\delta_{\max }$ is evaluated from the measured void fraction as follows:

$$
\alpha=\frac{\left(D-2 \cdot \delta_{\max }\right)^{2}}{D^{2}} .
$$

Under the hypothesis of pure annular flow, the liquid film velocity $U_{l}$ and the core gas velocity $U_{g}$ are evaluated as follows:

$$
\begin{gathered}
U_{g}=\frac{J_{g}}{\alpha}, \\
U_{l}=\frac{J_{l}}{1-\alpha} .
\end{gathered}
$$

In Figure 13, the liquid film thickness is shown as a function of the superficial velocity of the two-phases.

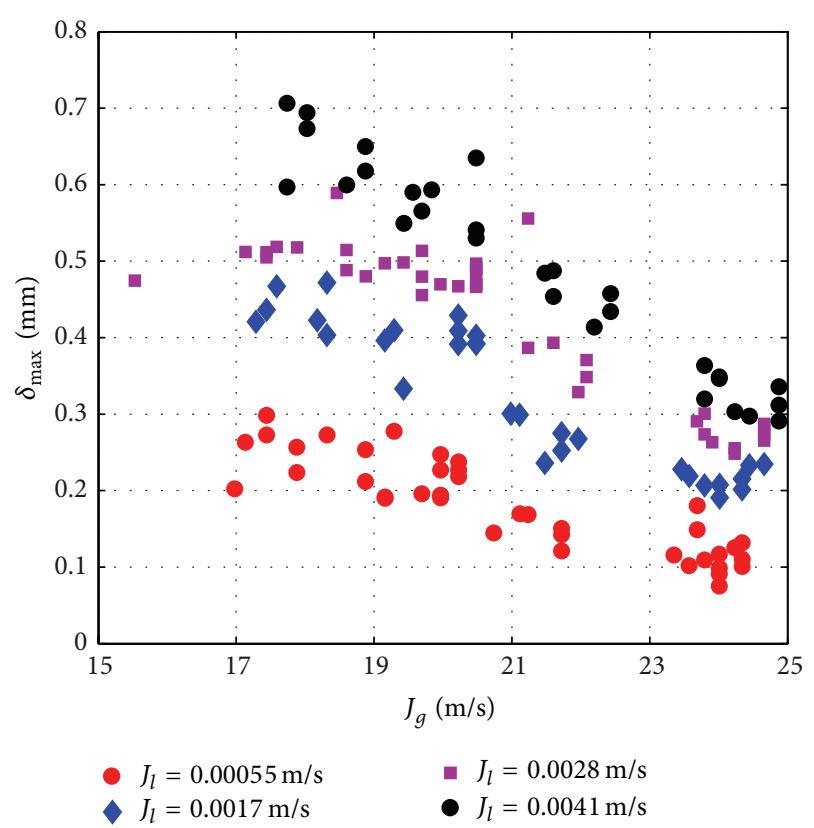

FIGURE 13: Maximum film thickness (7) as a function of the experimental water and air superficial velocity.

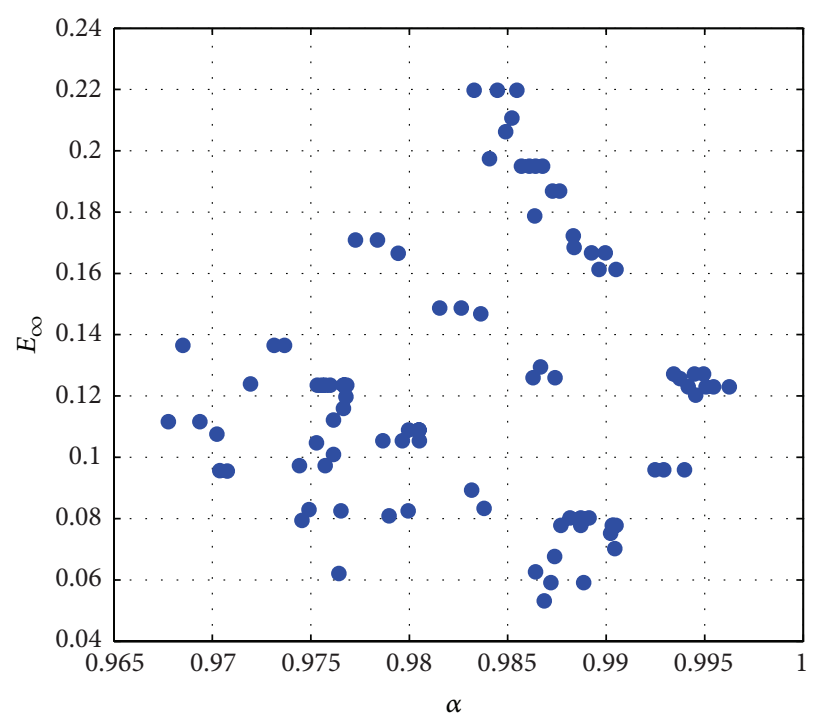

FIGURE 14: Equilibrium entrainment (4) as a function of the experimental volumetric void fraction $\alpha$.

Actually this model is valid for the pure annular flow pattern, but, by introducing the correction due to the entrainment (Figure 14), the core gas fraction is evaluated more correctly. The velocities of the phases are corrected assuming the same liquid droplets velocity as that of the gas in the core region:

$$
\begin{gathered}
U_{g}=\frac{J_{g}}{\left(\alpha_{c}-\alpha_{d}\right)}, \\
U_{l}=\left(1-E_{\infty}\right) \cdot U_{f}+E_{\infty} \cdot U_{g}, \\
U_{f}=\left(1-E_{\infty}\right) \cdot \frac{J_{l}}{\left(1-\alpha_{c}\right)} .
\end{gathered}
$$

The velocity of the two-phases is shown in Figures 15 and 16. 


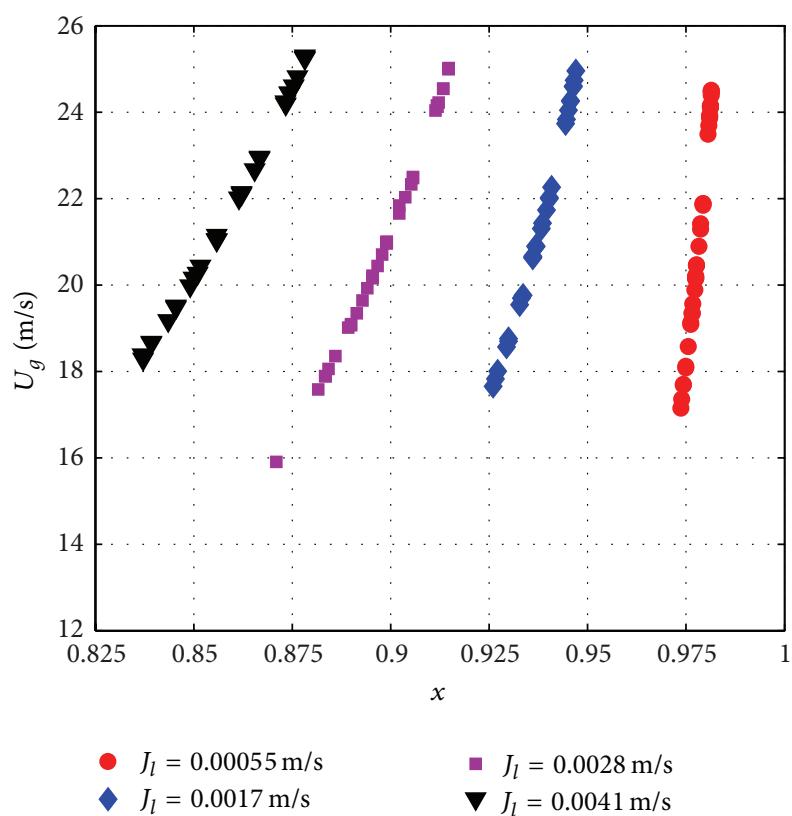

FIGURE 15: Air velocity as a function of the experimental flow quality (9).

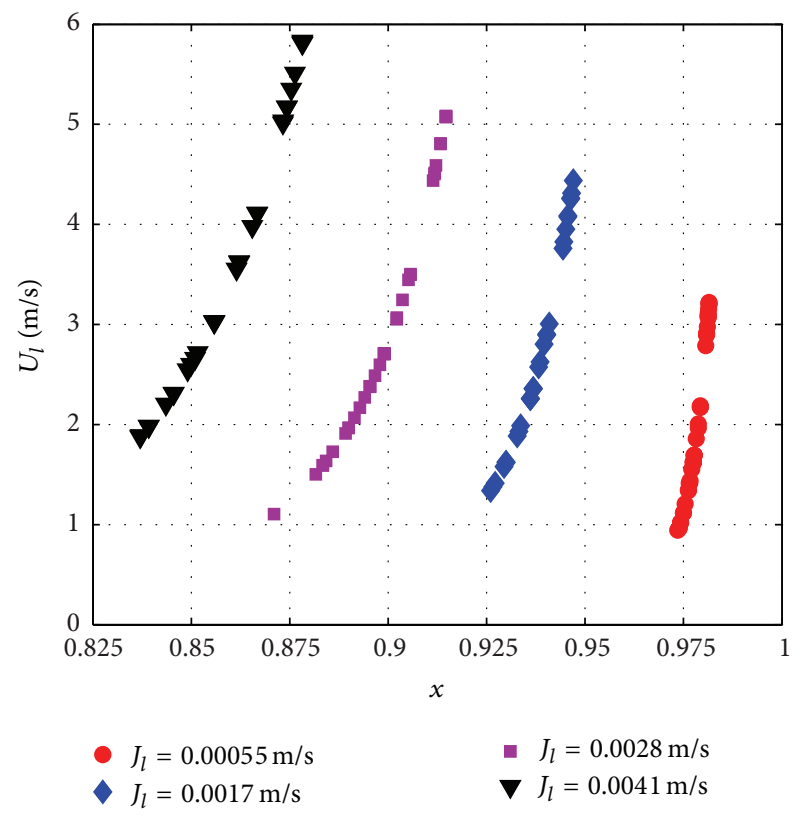

FIGURE 16: Water velocity as a function of the experimental flow quality (10).

In Figure 17, the derived slip ratio $\left(S=U_{g} / U_{l}\right)$ is shown as a function of the flow quality, at different liquid superficial velocity.

The liquid film thickness is corrected, as shown in Figure 18, taking into account the amount of liquid that is entrained into the core region:

$$
\alpha_{c}=\frac{(D-2 \cdot \delta)^{2}}{D^{2}}
$$

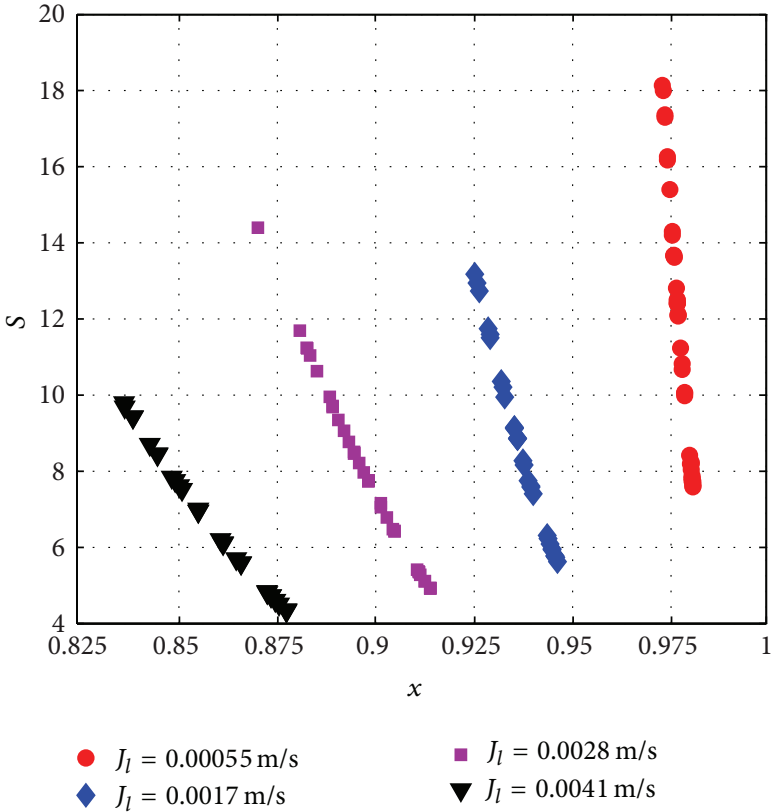

FIGURE 17: Slip ratio $S=U_{g} / U_{l}$ (evaluated on the basis of Ishii's model) as a function of the experimental flow quality.

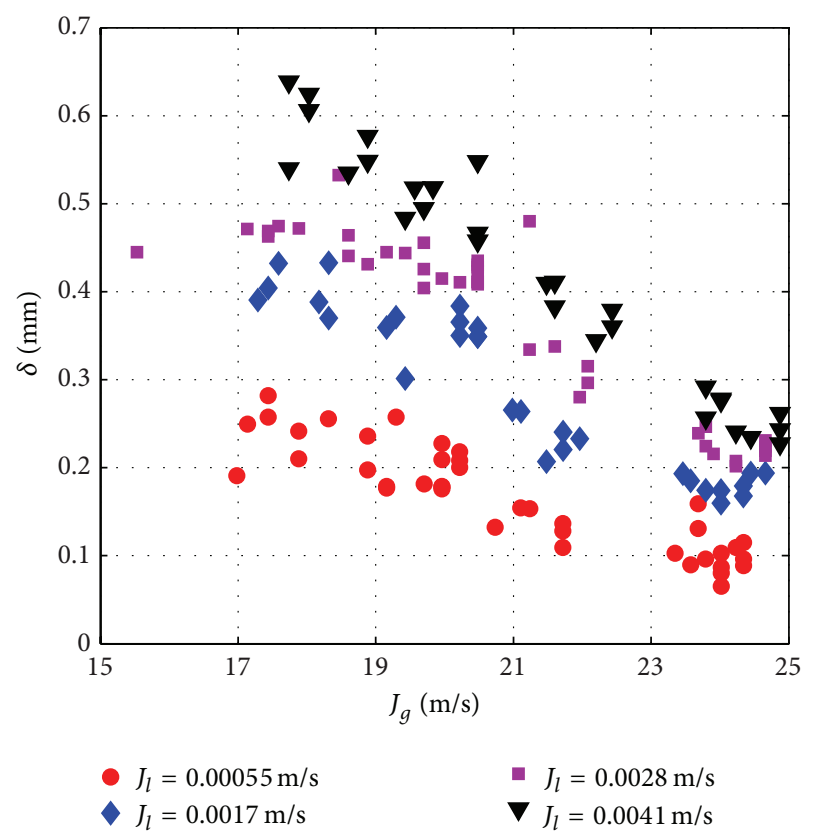

FIgURE 18: Corrected mean film thickness as a function of the experimental water and air superficial velocities.

In order to analyze the dependence of the sensor signals on the measured void fraction, the data of the different electrodes combination are related to the liquid film thickness $\delta$ by means of the core void fraction $\alpha_{c}$ and to the liquid fraction in the core region by means of the droplets fraction $\alpha_{d}$. A model correlating the probe signals to the two-phase flow parameters, as $\alpha_{c}, \alpha_{d}, J_{l}, J_{g}$, pressure $p$, geometry, and 


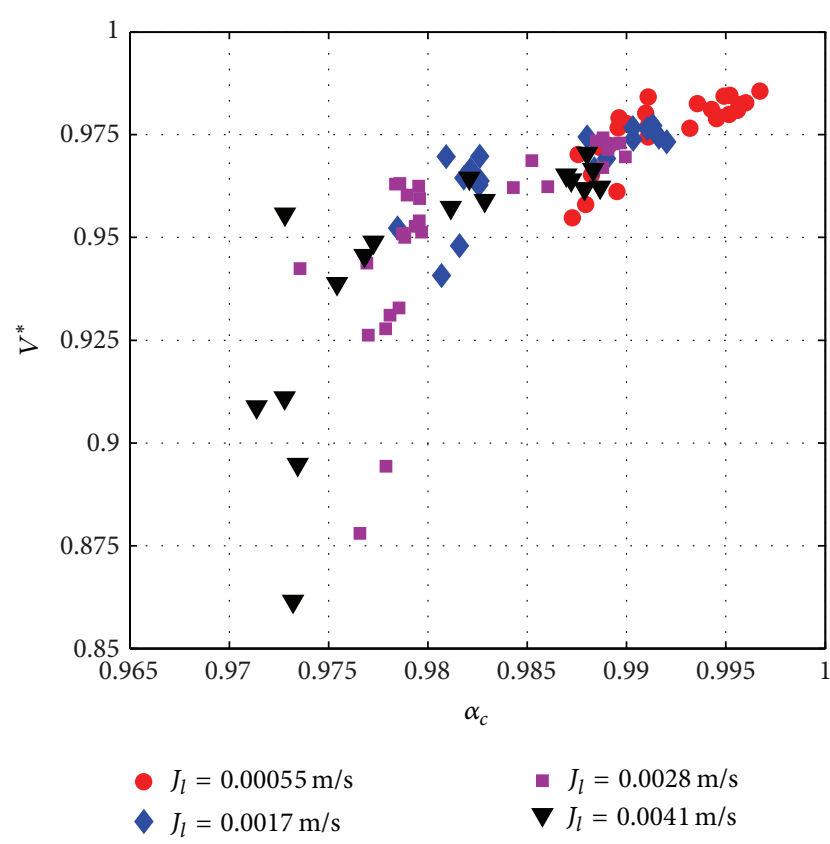

FIGURE 19: Normalized average signals of the central electrode, as a function of the core void fraction (evaluated on the basis of Ishii's model).

fluid parameters is required. For an axial symmetrical twophase flow at constant pressure and temperature, a simple model with two parameters and two signals (from an external electrode and from the central one) can estimate the film thickness, the liquid core droplet fraction, and the void fraction. In Figure 19, the signals measured in the central electrode are shown as a function of the core fraction. The flow pattern characteristics, from rather regular to more disturbed annular flow, are clearly detected. In Figure 20, the same signal is evaluated as a function of the droplets fraction: the internal probe is more sensitive than the external ones to the effect of the liquid and gas velocity change.

In the future, the direct measurement of the local liquid film thickness and of the frequency of the film waves will be performed and their influence will be considered in the signal analysis.

Figure 21 shows the evolution of the signals with the film thickness, evaluated using the Ishii model, for the different measuring angles. The dependence is linear for all the angles, but the intercept coefficient (b) and the slop (a) of the best-fit curves depend on the angle $\theta$, as reported in Figure 22.

\section{Conclusions}

The paper presents the characterization of an electrical capacitance probe (ECP) that has been developed by the SIET Company and that consists of ten measurement electrodes, nine external and an internal one. The presence of the internal electrode introduces a little flow disturbance but allows one to obtain important information on the phase distribution inside the core region of the annular flow.

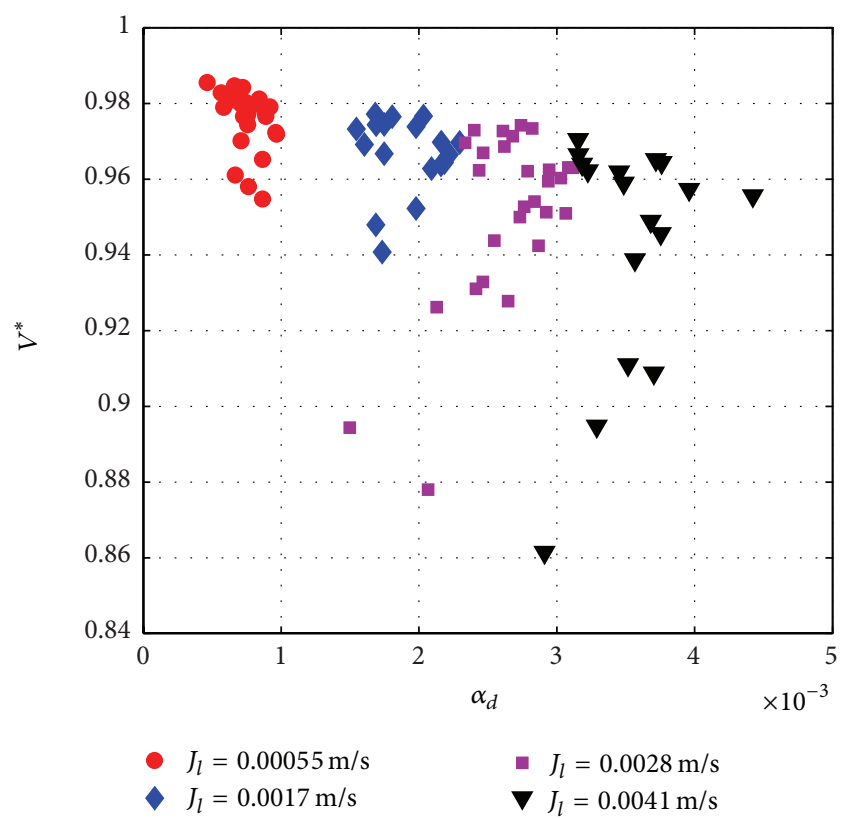

FIgURE 20: Normalized average signals of the central electrode, as a function of the core droplets fraction (evaluated on the basis of Ishii's model) at different experimental liquid superficial velocities.

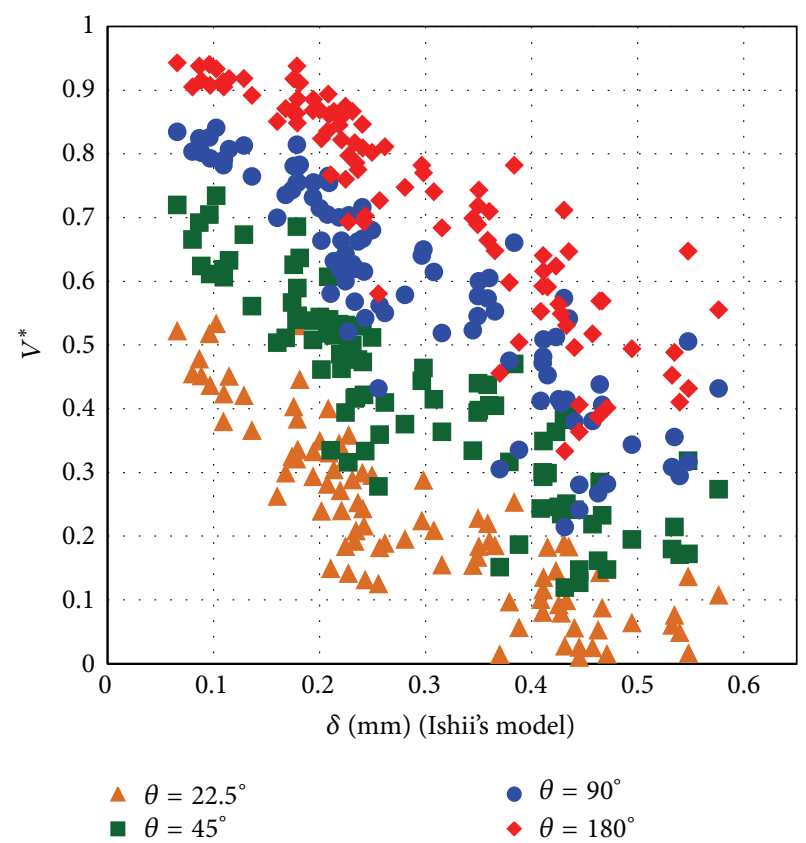

FIGURE 21: Average signal measured in the external electrodes as a function of the liquid film thickness (evaluated on the basis of Ishii's model).

The response of the sensor has been characterized in terms of single-phase flow sensitivity and signal variation dependence; geometry and fluid-dynamic influences on the signal have been investigated. Although the sensitivity in single-phase flow is low, two-phase flow void fraction variations lower than $1 \%$ have been detected. The presence of 


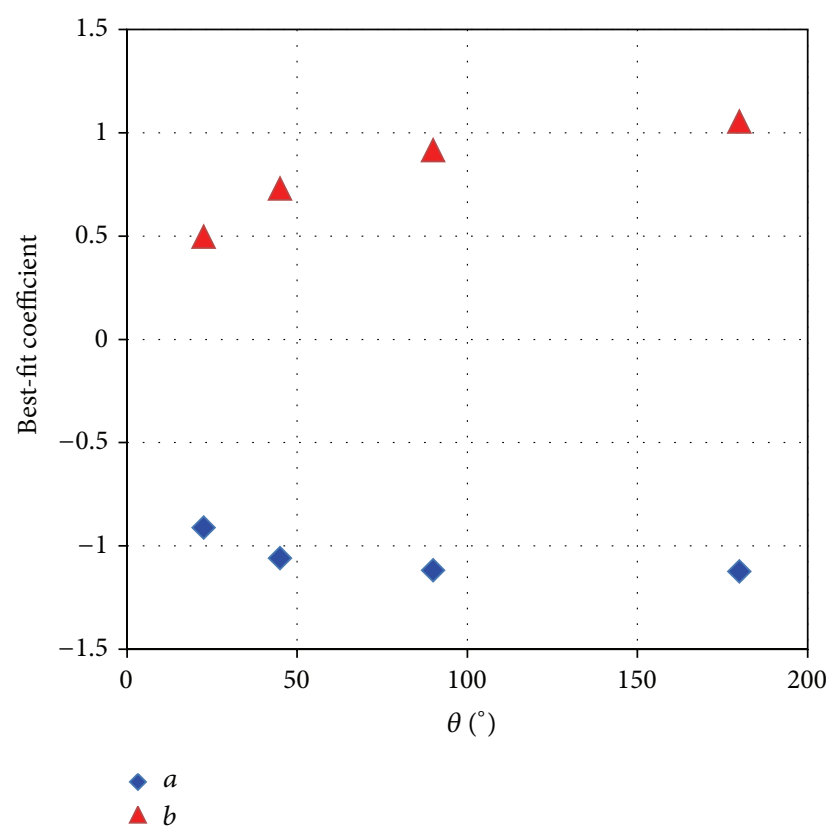

FIGURE 22: Best-fit coefficient dependence on the measuring angle for the curves shown in Figure 21; $a$ : slope, $b$ : intercept.

the central electrode allows the evaluation of the average cross section void fraction also in annular flow, where the liquid film is the principal cause of the sensor low sensitivity. The signal measured in the central electrode is linear with the void fraction for values higher than $98 \%$ and it is quite sensitive to the flow pattern: the flow pattern, from rather regular to more disturbed annular flow, has been clearly characterized. The variation of the signal measured in the external electrodes has been related to the average liquid film thickness that is evaluated by means of a simple model. The tests have shown the potentiality of this technology for the measurement of two-phase flow parameters at very high void fraction conditions (higher than 95\%).

On the ground of the present experimental results, the local film thickness and the frequencies of the film waves will be investigated in order to develop a model of the sensor suitable to evaluate the chordal void fractions and other fluid-dynamic parameters, also for a higher measurement parameters range. In this context, the time analysis of the electrodes signals can be carried out to identify such important fluid-dynamic parameters as well as the film interface oscillations.

In order to evaluate the performance of the sensor in the entire range of the flow patterns that are expected during the transient accident at the SPES3 facility, according to RELAP5 simulation, new experimental tests are currently underway, while the SIET Company is developing a sensor, having the same geometry of the present ECP, which is able to operate at the real break line conditions $\left(200^{\circ} \mathrm{C}\right.$ and 15 bar) [16]. In order to operate at high temperature and pressure, the Plexiglas pipe, in which the electrodes are located, has been substituted with a Pyrex pipe, and for safety purpose the sensor has been located inside a stainless steel pipe that can be pressurized from outside; the new probe has been thermally and mechanically tested and it is now ready for thermal-hydraulic tests. Moreover, in order to evaluate the mass flow rate of the phases during a LOCA, the experimental characterization of a Spool Piece, including the ECP, is underway at Politecnico di Torino.

\section{Nomenclature}

\author{
A : Area \\ D: Diameter \\ $E_{\infty}:$ Equilibrium entrainment \\ $f: \quad$ Signal frequency \\ $J: \quad$ Superficial velocity \\ Re: Reynolds number \\ S: $\quad$ Slip ratio \\ $U$ : Fluid velocity \\ $V^{*}$ : Normalized signal \\ We: Weber number \\ $x$ : Flow quality.
}

\section{Greek Characters \\ $\alpha$ : Void fraction \\ $\delta$ : Film thickness \\ $\theta$ : Angle between electrodes \\ $\mu$ : Dynamic viscosity \\ $\rho$ : Density \\ $\sigma$ : Surface tension.}

\author{
Subscripts \\ ac: Acquisition \\ $c$ : Core \\ d: Droplets \\ ex: Excitation \\ $f:$ Film \\ $g:$ Gas \\ $i$ - $j$ : Electrode index \\ $l$ : Liquid \\ TP: Two-phase.
}

\section{Abbreviations}

DAQ: Data AcQuisition

ECP: Electrical capacitance probe

LOCA: Loss of coolant accident

PWR: Pressurized water reactor

QCV: Quick-closing valve

RMS: Root mean square

SP: $\quad$ Spool Piece

SPES3: Simulator for PWR safety experiments.

\section{Conflict of Interests}

The authors declare that there is no conflict of interests regarding the publication of this paper. 


\section{Acknowledgments}

The present research has been supported by ENEA and by the Ministry of Economic Development. The authors wish to thank R. Costantino and G. Vannelli for their technical support.

\section{References}

[1] M. Carelli, L. Conway, M. Dzodzo et al., "The SPES3 experimental facility design for the IRIS reactor simulation," Science and Technology of Nuclear Installations, vol. 2009, Article ID 579430, 12 pages, 2009.

[2] R. Ferri, A. Achilli, C. Congiu et al., "SPES3 facility and IRIS reactor numerical simulations for the SPES3 final design," in Proceedings of the European Nuclear Conference (ENC '10), Barcelona, Spain, May 2010.

[3] M. Greco, R. Ferri, A. Achilli et al., "Two-phase flow measurement studies for the SPES3 integral test facility for IRIS reactor simulation," in Proceedings of The 18th International Conference on Nuclear Engineering (ICONE '18), pp. 305-316, Xi'an, China, May 2010.

[4] M. De Salve, G. Monni, and B. Panella, "State of art and selection of techniques in multiphase flow measurement," Report RdS/2010/67, ENEA, 2010.

[5] C. Bertani, M. De Salve, M. Malandrone, G. Monni, B. Panella, and A. Mosetto, "SPES-3 facility analysis," Report RdS/2010/68, ENEA, reference data for postulated accident simulation; criteria for general and special instrumentation selection, 2010.

[6] M. S. Rochal, E. L. L. Cabral, and J. R. Simões-Moreira, "Capacitance sensor for void fraction measurement in a natural circulation refrigeration circuit," in Proceedings of the International Nuclear Atlantic Conference (INAC '09), 2009.

[7] Z. Huang, B. Wang, and H. Li, "Application of electrical capacitance tomography to the void fraction measurement of two-phase flow," IEEE Transactions on Instrumentation and Measurement, vol. 52, no. 1, pp. 7-12, 2003.

[8] Y. Wu, H. Li, M. Wang, and R. A. Williams, "Characterization of air-water two-phase vertical flow by using electrical resistance imaging," Canadian Journal of Chemical Engineering, vol. 83, no. 1, pp. 37-41, 2005.

[9] W. Warsito and L. S. Fan, "Measurement of real-time flow structures in gas-liquid and gas-liquid-solid flow systems using electrical capacitance tomography (ECT)," Chemical Engineering Science, vol. 56, no. 21-22, pp. 6455-6462, 2001.

[10] R. Ferri and C. Congiu, "SPES3-IRIS facility RELAP5 base case transient analyses for design support," SIET Document 01489 RT 09 Rev.0, 2009.

[11] A. W. Bennett, G. F. Hewitt, H. A. Kearsey, R. K. F. Keeys, and M. P. C. Lacey, "Flow visualisation studies of boiling at high pressure," Proceedings of the Institution of Mechanical Engineers, vol. 180, part 3C, pp. 1-11, 1965.

[12] G. F. Hewitt and D. N. Roberts, "Studies of two-phase flow patterns by simultaneous X-ray and flash photography," UKAEA Report AERE-M 2159, London, UK, 1969.

[13] M. Ishii and K. Mishima, "Two-fluid model and hydrodynamic constitutive relations," Nuclear Engineering and Design, vol. 82, no. 2-3, pp. 107-126, 1984.

[14] T. Hazuku, T. Takamasa, T. Hibiki, and M. Ishii, "Interfacial area concentration in annular two-phase flow," International Journal of Heat and Mass Transfer, vol. 50, no. 15-16, pp. 2986-2995, 2007.
[15] T. Okawa, A. Kotani, N. Shimada, and I. Kataoka, "Effects of a flow obstacle on the deposition rate of droplets in annular twophase flow," Journal of Nuclear Science and Technology, vol. 41, no. 9, pp. 871-879, 2004.

[16] C. Randaccio, "Prove a caldo di una sonda capacitiva per la misura del grado di vuoto in miscela bifase," SIET Document 01876 RP 12, 2012. 


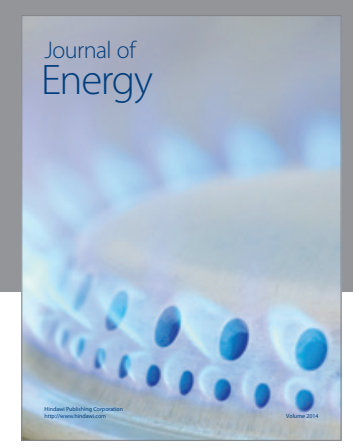

Journal of

Industrial Engineering
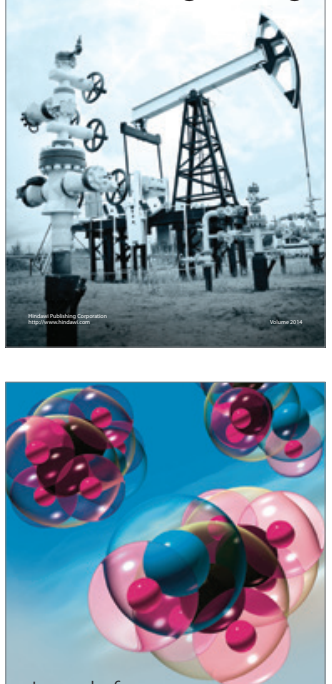

Fuels
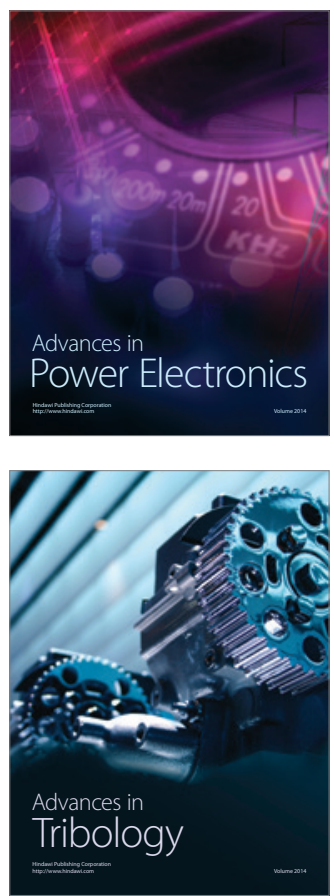

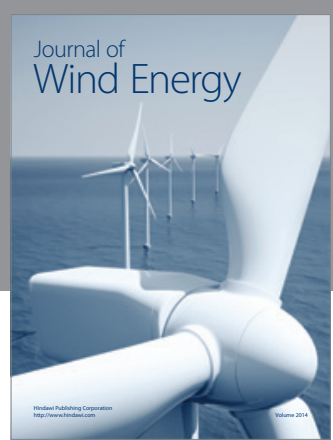

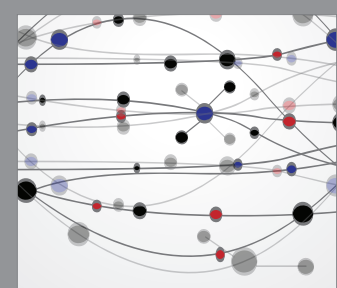

The Scientific World Journal

Submit your manuscripts at http://www.hindawi.com

Journal of

Structures
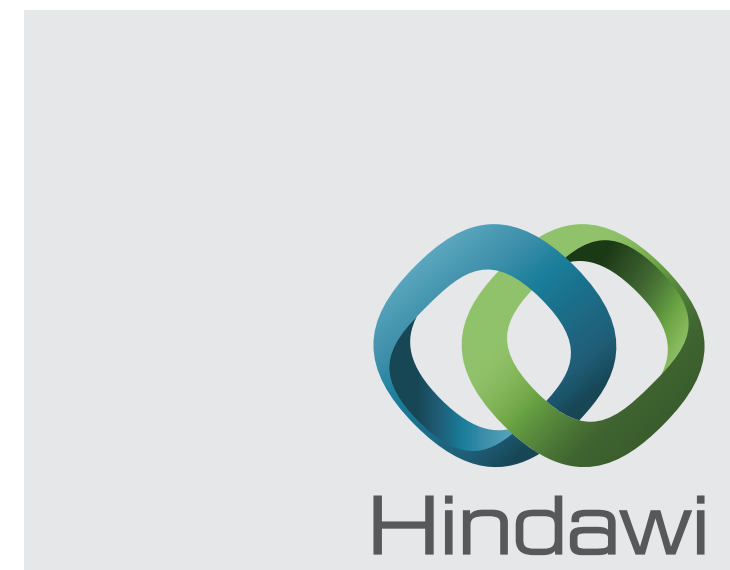

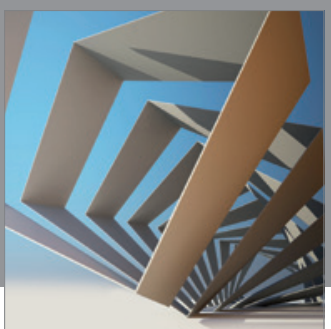

Rotating

Machinery
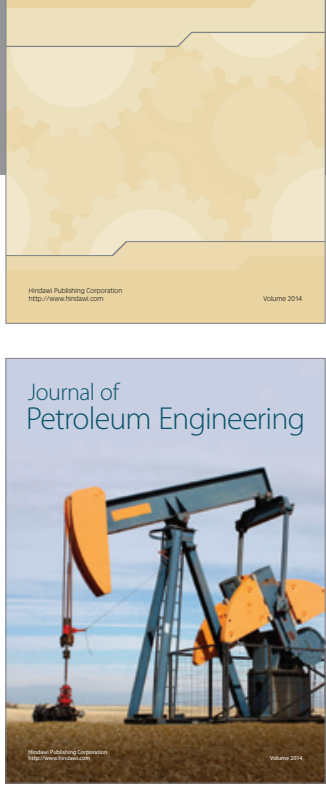

Journal of

Solar Energy
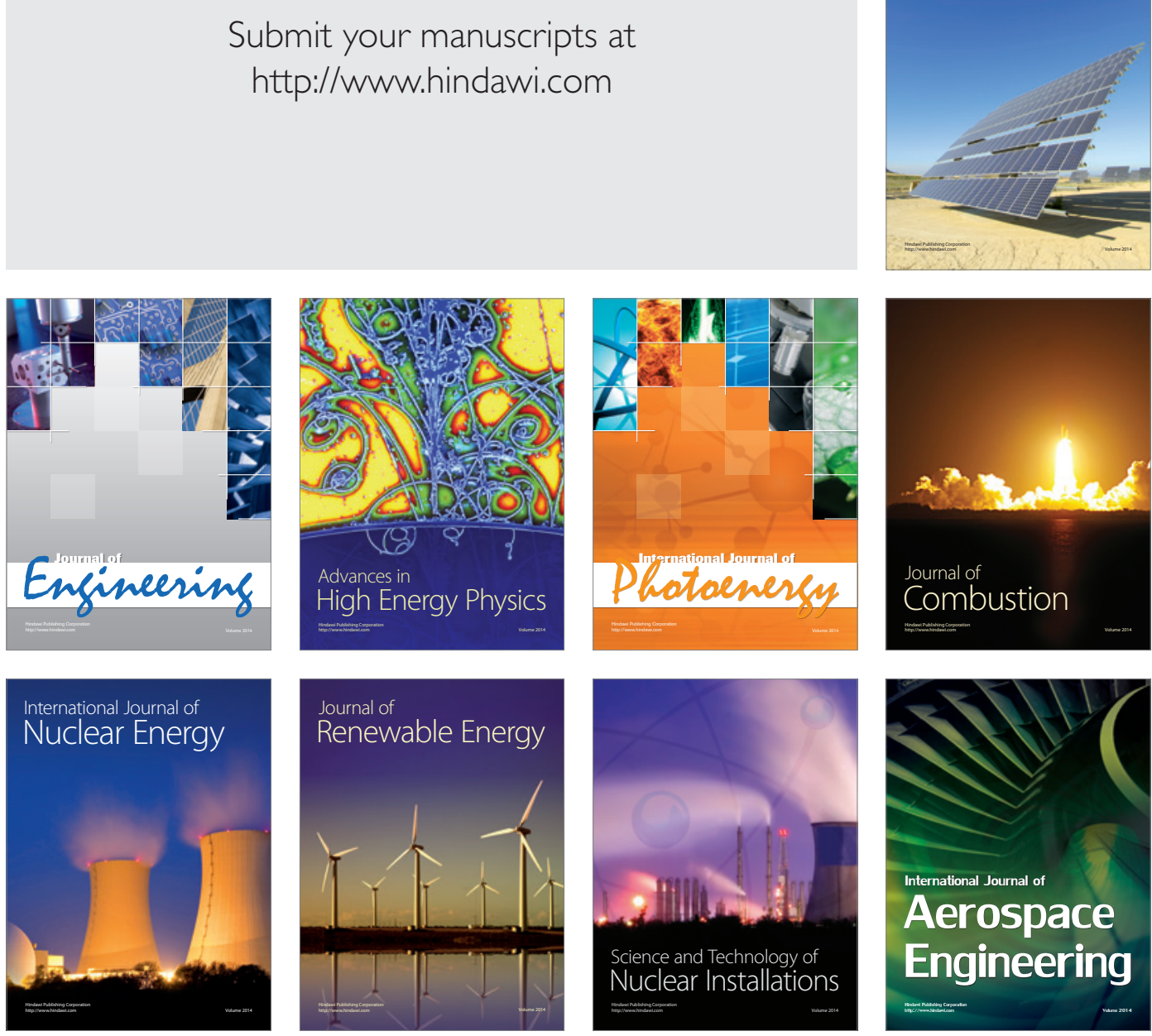